\title{
Study on the size-segregated distribution of 37 species of polycyclic aromatic hydrocarbons in urban atmospheric fine particles of Japan
}

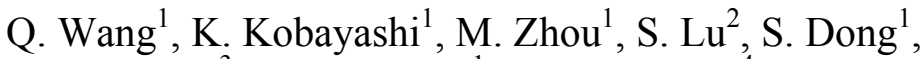 \\ D. Nakajima ${ }^{3}$, K. Sekiguchi ${ }^{1} \&$ M. Terasaki ${ }^{4}$ \\ ${ }^{1}$ Graduate School of Science and Engineering Saitama University, Japan \\ ${ }^{2}$ Shanghai University, China \\ ${ }^{3}$ National Institute for Environmental Studies, Japan \\ ${ }^{4}$ University of Shizuoka, Japan
}

\begin{abstract}
The size-segregated distribution and seasonal concentrations of polycyclic aromatic hydrocarbons (PAHs) in urban suspended particulate matter (SPM) at the Japan national route 463 in the urban of Saitama city, Japan were investigated using an Andersen high-volume air sampler. Air sampling was carried out from June 2013 to January 2014. 37 species of toxic PAHs such as benzo $[j]$ aceanthrylene, dibenzo $[a, h]$ anthracene, benzo $[c]$ fluorene and dibenzo[ $[a, l]$ pyrene were measured. It was found that the average concentration of 37 species of particulate PAHs including methyl-PAHs, benzothiophenes and oxy-PAHs from atmospheric oxidation of PAHs collected in the urban of Saitama city was 3.42 to $6.51 \mathrm{ng} / \mathrm{m}^{3}$ during 2013 sampling campaign periods. 1,8-naphthalic anhydride (1,8-NA) showed the highest concentration among 37 species of PAHs. The concentrations of high molecular PAHs, which were found in all seasons, followed different size distribution, especially with the highest peak in fine particle sizes around $1.1 \mu \mathrm{m}$. The concentrations of low-molecular PAHs were not much different with particle sizes. The toxicity analysis indicated that the carcinogenic potency of particulate PAHs primarily existed in the particle size below $1.1 \mu \mathrm{m} .37$ species of PAHs in urban atmospheric fine particles were not only derived from vehicle emission with long range transportation, but also produced by local other anthropogenic sources.

Keywords: suspended particulate matter, size distribution, PAHs, toxicity.
\end{abstract}




\section{Introduction}

The urban environment is heavily impacted by suspended particulate matter (SPM) generated mainly from fossil fuel combustion, industries, and others; however, vehicular traffic has been one of the major sources of air pollution by polycyclic aromatic compounds (PACs) [1]. USEPA and other regulatory agencies have designated some polycyclic aromatic hydrocarbons (PAHs) as priority pollutants, the measurement is targeted for the environment samples [2]. The biomonitoring in environmental samples is extremely difficult because PAHs occur in complex mixtures in the environment [2]. PAHs are among the most risky extracted organic compounds because of their carcinogenic [3] and genotoxic properties [4], associated with atmospheric particles of different sizes $[5,6]$ which can influence their deposition in human lungs. Also, oxygenated PAH (oxy-PAH) compounds are persistent and bioaccumulative with toxic, mutagenic, carcinogenic and estrogenic properties [7]. The toxic properties of some oxy-PAHs are higher than those of their parent-PAHs [8].

The elucidation of the size distributions of PAHs is essential to estimate their inputs into ecosystems and the human respiratory system, to trace their origins and to understand their ageing process [9]. Therefore, it is important to study the size distributions of PAHs in urban atmospheric particles.

Recently, it was pointed out that benzo[j]aceanthrylene, dibenzo $[a, h]$ anthracene, benzo $[c]$ fluorene and dibenzo $[a, l]$ pyrene are more toxic than benzo[a]pyrene [10]. However, the study report about atmospheric concentrations of these PAHs is few. Additionally, study on the size distributions of these PAHs is previously unreported. Here, in this study, we report the size-segregated distribution and seasonal behaviors of 37 species of PAHs in urban atmospheric particles in Saitama city based on investigation of intermittent twelve weeks from June 2013 to January 2014.

\section{Materials and methods}

\subsection{Ambient sampling for urban suspended particulate matter}

Ambient sampling was specifically conducted at near a roadside of Japan national route 463 with the traffic density around 40,000-60,000 vehicles per day, where located in the front of the Okubo campus, the School and Graduate School of Science and Engineering of Saitama University in Sakura-Ku in urban of Saitama city, Japan.

Size-segregated samples of suspended particulate matter were collected on the quartz fiber filters $\left(8 \times 10 \mathrm{inch}^{2}\right.$, Pallflex Product, 2500QATUP) using an Andersen high-volume air sampler (HV-600F, Shibata Co., Tokyo, Japan) equipped with five stages of an Andersen impactor (Shibata Co., Tokyo, Japan). Five size-segregated fractions of urban atmospheric particulate samples are fine and coarse particles at the particle sizes ranging from $\leqq 1.1,1.1-2.0,2.0-3.3$, $3.3-7.0$ and $\geqq 7.0 \mu \mathrm{m}$. Quartz fiber filters were used for collecting ambient particle samples because they are thermally resistant and can be heat-treated to 
remove any PAHs present in the blank filter before sampling. The sampling time was one week (167 hours), and the sample flow rate was $0.566 \mathrm{~m}^{3} \mathrm{~min}^{-1}$. The sampling campaign periods was conducted intermittently for twelve weeks in June, July, August, September, October, November and December 2013 and January 2014. In this study, sampling artifacts were not taken into consideration. This is because: a) completely reliable and standardized methods for correction of sampling artifacts have not yet been developed due to the many factors and complexity involved; and b) if the artifacts did influence the concentrations of PAHs, the effect would be expected to be similar in each sample, and consequently this would not alter the conclusions of this study. In this study, we only investigated the spatial and temporal changes in concentrations of PAHs.

During the sampling campaign periods, the relative humidity in Saitama city covered a range of $45 \%-74 \%$ [11], and the temperatures varied from 3.8 to $28.4^{\circ} \mathrm{C}$. The sampling sites were located at the roadside. The samples that were used for the investigation of daily and seasonal variations in concentrations of PAHs. After collection, the filter samples were dried at room temperature. All the filters were then stored at $-30^{\circ} \mathrm{C}$ until being submitted for analysis.

\subsection{Standard chemicals of 37 species of PAHs}

The standard chemicals of 37 species of PAHs including methyl-PAHs, benzothiophenes and oxy-PAHs for analysis of urban atmospheric particles are commercial production as follow.

Napthalene (Nap), acenaphthylene (Acy), acenaphthene (Ace), fluorene (Flu), Phenanthrene (Phe), anthracene (Ant), fluoranthene (FLN), pyrene (Pyr), benz $[a]$ anthracene (BaA), chrysene (Chy), benzo[b]fluoranthene (BbF), benzo $[k]$ fluoranthene $(\mathrm{BkF}), \quad$ benzo $[a]$ pyrene $(\mathrm{BaP})$, dibenz $[a, h]$ anthracene (dBahA), indeno[1,2,3-cd]pyrene (IndP) and benzo[g,h,i]perylene (BghiP) were obtained from Sigma Sigma-Aldrich.

3-methylphenanthrene (3-MP), 2-methylphenanthrene (2-MP), 9-methylphenanthrene (9-MP) and 1-methylphenanthrene (1-MP) were obtained from Dr. Ehrenstorfer GmbH.

1,8-naphthalic anhydride (1,8-NA) was obtained from Tokyo Kasei Kogyo, Tokyo, Japan.

$5 \mathrm{H}$-phenanthro[4,5-bcd]pyran-5-one (PPO) was obtained from University of Shizuoka, Shizuoka, Japan.

Dibenzothiophene (DBT), fluoren-9-one, retene (Re), benzo[c]fluorine $(\mathrm{BcF})$, benzo[b]naphtho[2,1-d]thiophene $(\mathrm{BN}(21 \mathrm{~d}) \mathrm{T})$, benzo[b]naphtho[1,2-d]thiophene $(\mathrm{BN}(12 \mathrm{~d}) \mathrm{T})$, cyclopenta[c,d]pyrene $(\mathrm{CP}(\mathrm{c}, \mathrm{d}) \mathrm{P})$, benzo[j]fluoranthene $(\mathrm{BjF})$, benz $[j]$ aceanthrylene $(\mathrm{B}(\mathrm{j}) \mathrm{AC})$, anthanthrene (AA), dibenzo[a,e]fluoranthene $(\mathrm{DB}(\mathrm{a}, \mathrm{e}) \mathrm{F})$, dibenzo[a,l]pyrene (DB(a,l)P), dibenzo[a,e]pyrene (DB(a,e)P), dibenzo $[a, i]$ pyrene $(\mathrm{DB}(\mathrm{a}, \mathrm{i}) \mathrm{P})$ and dibenzo $[a, h]$ pyrene $(\mathrm{DB}(\mathrm{a}, \mathrm{h}) \mathrm{P})$ were obtained from Wako Pure Chemical Industries, Tokyo, Japan.

Internal standards of napthalene- $\mathrm{d} 8$, acenaphthylene-d10, acenaphthene-d10, fluorene-d10, phenanthrene-d10, anthracene-d10, fluoranthene-d10, pyrene-d10, benz $[a]$ anthracene-d12, chrysene-d12, benzo $[b]$ fluoranthene-d12, benzo $[k]$ fluoranthene-d12, benzo $[a]$ pyrene-d12, dibenz $[a, h]$ anthracene-d14, 
indeno $[1,2,3-c d]$ pyrene-d12 and benzo[ $g, h, i]$ perylene-d12 were obtained from CIL, Inc., Tokyo, Japan. Here, the meaning of $d$ in each compound of PAH is deuterium. All standard chemicals of 37 species of PAHs including methyl-PAHs, benzothiophenes and oxy-PAHs were used without further purification.

\subsection{Analysis of PAHs with the GC/MS method}

An aliquot of each filter was cut into small pieces and put in a flask, followed by addition of internal standards of PAHs. The samples were then extracted ultrasonically for $10 \mathrm{~min}$ three times with dichloromethane (DCM) and the extract solution was filtered to remove any solid material. The filtrate was evaporated to rotary evaporator (600 torr). After that, the residue was dissolved in $30 \mathrm{~mL}$ of $\mathrm{n}$-hexane and evaporated to rotary evaporator (180 torr). After that the residue was cleaned by solid phase extraction (SPE) with a silica gel solid phase (Sep-Pak Silica Plus Long Cartridge $690 \mathrm{mg}$ Sorbent per Cartridge 55-105 $\mu \mathrm{m}$ Particle Size 50/pk, Waters). The extract solution added to n-nonane and was evaporated to dryness under a stream of $\mathrm{N}_{2}$. The extract solution was concentrated to $0.1 \mathrm{~mL}$ and submitted to a Gas Chromatography Mass Spectrometry (GC/MS, Model Agilent 5973N) used for analysis of PAHs.

The concentrations of PAHs the extract solution were quantified with a GC/MS system. GC/MS analyses were performed on a InertCap 17 column $(0.25 \mathrm{~mm}$ i.d. $\times 30 \mathrm{~m}$ and $0.25 \mu \mathrm{m}$ film thickness $)$ using an HP6890 GC interfaced into an HP5973 MS detector. The initial column temperature was $50^{\circ} \mathrm{C}$ and held at this temperature for $2 \mathrm{~min}$. After that temperature increased at $15^{\circ} \mathrm{C} \mathrm{min}^{-1}$ to $185^{\circ} \mathrm{C}$ and then increased at $8^{\circ} \mathrm{C} \mathrm{min}^{-1}$ to $320^{\circ} \mathrm{C}$ and held at this temperature for $22 \mathrm{~min}$. MS detection was run in selected ion monitoring (SIM) mode. The injections were splitless, and the sample volume was $1 \mu \mathrm{L}$. High-purity helium was used as the carrier gas at a constant flow rate of $1.3 \mathrm{~mL}$ $\mathrm{min}^{-1}$. The identification of the individual PAHs was based on the retention times of target ion peaks (within $\pm 0.05 \mathrm{~min}$ of the retention of the calibration standard). The data acquisition and processing were controlled using HP Chemstation software installed in GC/MS of Model Agilent 5973N.

\subsection{Quality control and statistical analysis of PAHs with GC/MS method}

In this study, field blanks of 37 species of PAHs were detected, which accompanied the samples to and from the sampling sites, were used to determine the background contamination levels. 16 species of PAHs consisting of napthalene-d8, acenaphthylene-d10, aAcenaphthene-d10, fluorene-d10, phenanthrene-d10, anthracene-d10, fluoranthene-d10, pyrene-d10, benz $[a]$ anthracene-d12, chrysene-d12, benzo[ $b]$ fluoranthene-d12, bnzo $[k]$ fluoranthene-d12, benzo $[a]$ pyrene-d12, dibenz $[a, h]$ anthracene-d14, indeno $[1,2,3-c d]$ pyrene-d12, benzo $[g, h, i]$ perylene-d12 standards (CIL, inc., Japan) were added to all of the samples to monitor the procedural performance and the matrix effects. The measured extraction recoveries for 16 species of PAHs were approximately $70 \%$ to $125 \%$. Because the recovery of naphthalene-d8 was very low, we will be better to show the detection limitation 
(LOD) and quantitation limitation (LOQ) of 37 species of PAHs based on GC/MS method given in table 1. The concentrations of 37 species of PAHs were determined by 6 times for each sample and made statistical analysis for the data processing.

Table 1: The detection limitation (LOD) and quantitation limitation (LOQ) of 37 species of PAHs determined by GC/MS method.

\begin{tabular}{|c|c|c|c|c|}
\hline Species of PAHs & Abbreviation & Chemical formula & $\operatorname{LOD}\left(\mathrm{ng} / \mathrm{m}^{3}\right)$ & $\mathrm{LOQ}\left(\mathrm{ng} / \mathrm{m}^{3}\right)$ \\
\hline Naphthalene & Nap & $\mathrm{C}_{10} \mathrm{H}_{8}$ & 0.0009 & 0.0031 \\
\hline Acenaphthylene & Acy & $\mathrm{C}_{12} \mathrm{H}_{8}$ & 0.0014 & 0.0047 \\
\hline Acenaphthene & Ace & $\mathrm{C}_{12} \mathrm{H}_{10}$ & 0.0014 & 0.0047 \\
\hline Fluorene & Flu & $\mathrm{C}_{13} \mathrm{H}_{10}$ & 0.0009 & 0.0029 \\
\hline Dibenzothiophene & DBT & $\mathrm{C}_{12} \mathrm{H}_{8} \mathrm{~S}$ & 0.0020 & 0.0065 \\
\hline Fluorene-9-one & & $\mathrm{C}_{13} \mathrm{H}_{8} \mathrm{O}$ & 0.0034 & 0.0114 \\
\hline Phenanthrene & Phe & $\mathrm{C}_{14} \mathrm{H}_{10}$ & 0.0026 & 0.0087 \\
\hline Anthracene & Ant & $\mathrm{C}_{14} \mathrm{H}_{10}$ & 0.0004 & 0.0012 \\
\hline 3-Methylphenanthrene & 3-MP & $\mathrm{C}_{15} \mathrm{H}_{12}$ & 0.0036 & 0.0121 \\
\hline 2-Methylphenanthrene & 2-MP & $\mathrm{C}_{15} \mathrm{H}_{12}$ & 0.0021 & 0.0069 \\
\hline 9-Methylphenanthrene & 9-MP & $\mathrm{C}_{15} \mathrm{H}_{12}$ & 0.0069 & 0.0230 \\
\hline 1-Methylphenanthrene & 1-MP & $\mathrm{C}_{15} \mathrm{H}_{12}$ & 0.0171 & 0.0570 \\
\hline Fluoranthene & FLN & $\mathrm{C}_{16} \mathrm{H}_{10}$ & 0.0010 & 0.0033 \\
\hline Retene & $\mathrm{Re}$ & $\mathrm{C}_{18} \mathrm{H}_{18}$ & 0.0020 & 0.0067 \\
\hline Pyrene & Pyr & $\mathrm{C}_{16} \mathrm{H}_{10}$ & 0.0009 & 0.0030 \\
\hline 1,8-Naphthalic anhydride & $1,8-\mathrm{NA}$ & $\mathrm{C}_{12} \mathrm{H}_{6} \mathrm{O}_{3}$ & 0.0018 & 0.0061 \\
\hline $\operatorname{Benzo}[c]$ fluorene & $\mathrm{BcF}$ & $\mathrm{C}_{17} \mathrm{H}_{12}$ & 0.0016 & 0.0054 \\
\hline 5H-Phenanthro[4,5- $b c d]$ pyran-5-one & PPO & $\mathrm{C}_{15} \mathrm{H}_{7} \mathrm{O}_{2}$ & 0.0017 & 0.0056 \\
\hline Benzo $[b]$ naphtho $[2,1-d]$ thiophene & $\mathrm{BN}(21 \mathrm{~d}) \mathrm{T}$ & $\mathrm{C}_{16} \mathrm{H}_{10} \mathrm{~S}$ & 0.0010 & 0.0035 \\
\hline Benzo $[b]$ naphtho $[1,2-d]$ thiophene & $\mathrm{BN}(12 \mathrm{~d}) \mathrm{T}$ & $\mathrm{C}_{16} \mathrm{H}_{10} \mathrm{~S}$ & 0.0010 & 0.0033 \\
\hline $\operatorname{Benz}[a]$ anthracene & $\mathrm{BaA}$ & $\mathrm{C}_{18} \mathrm{H}_{12}$ & 0.0014 & 0.0047 \\
\hline Cyclopenta $[c, d]$ pyrene & $\mathrm{CP}(\mathrm{c}, \mathrm{d}) \mathrm{P}$ & $\mathrm{C}_{18} \mathrm{H}_{10}$ & 0.0031 & 0.0103 \\
\hline Chrysene & Chy & $\mathrm{C}_{18} \mathrm{H}_{12}$ & 0.0017 & 0.0057 \\
\hline Benzo $[b]$ fluoranthene & $\mathrm{BbF}$ & $\mathrm{C}_{20} \mathrm{H}_{12}$ & 0.0020 & 0.0068 \\
\hline Benzo $[k]$ fluoranthene & $\mathrm{BkF}$ & $\mathrm{C}_{20} \mathrm{H}_{12}$ & 0.0001 & 0.0002 \\
\hline Benzo $[j]$ fluoranthene & $\mathrm{BjF}$ & $\mathrm{C}_{20} \mathrm{H}_{12}$ & 0.0047 & 0.0158 \\
\hline Benz $[j]$ aceanthrylene & $\mathrm{B}(\mathrm{j}) \mathrm{AC}$ & $\mathrm{C}_{20} \mathrm{H}_{12}$ & 0.0045 & 0.0150 \\
\hline Benzo $[a]$ pyrene & $\mathrm{BaP}$ & $\mathrm{C}_{20} \mathrm{H}_{12}$ & 0.0014 & 0.0045 \\
\hline $\operatorname{Dibenz}[a, h]$ anthracene & $\mathrm{dBahA}$ & $\mathrm{C}_{22} \mathrm{H}_{14}$ & 0.0023 & 0.0078 \\
\hline Indeno $[1,2,3-c d]$ pyrene & IndP & $\mathrm{C}_{22} \mathrm{H}_{12}$ & 0.0010 & 0.0033 \\
\hline Benzo $[g, h, i]$ perylene & BghiP & $\mathrm{C}_{22} \mathrm{H}_{12}$ & 0.0009 & 0.0032 \\
\hline Anthanthrene & $\mathrm{AA}$ & $\mathrm{C}_{22} \mathrm{H}_{12}$ & 0.0014 & 0.0048 \\
\hline $\operatorname{Dibenzo}[a, e]$ fluoranthene & $\mathrm{DB}(\mathrm{a}, \mathrm{e}) \mathrm{F}$ & $\mathrm{C}_{24} \mathrm{H}_{14}$ & 0.0007 & 0.0024 \\
\hline Dibenzo $[a, l]$ pyrene & $\mathrm{DB}(\mathrm{a}, \mathrm{l}) \mathrm{P}$ & $\mathrm{C}_{24} \mathrm{H}_{14}$ & 0.0034 & 0.0112 \\
\hline Dibenzo $[a, e]$ pyrene & $\mathrm{DB}(\mathrm{a}, \mathrm{e}) \mathrm{P}$ & $\mathrm{C}_{24} \mathrm{H}_{14}$ & 0.0028 & 0.0093 \\
\hline Dibenzo $[a, i]$ pyrene & $\mathrm{DB}(\mathrm{a}, \mathrm{i}) \mathrm{P}$ & $\mathrm{C}_{24} \mathrm{H}_{14}$ & 0.0011 & 0.0036 \\
\hline Dibenzo $[a, h]$ pyrene & $\mathrm{DB}(\mathrm{a}, \mathrm{h}) \mathrm{P}$ & $\mathrm{C}_{24} \mathrm{H}_{14}$ & 0.0006 & 0.0018 \\
\hline
\end{tabular}




\section{Results and discussions}

\subsection{Seasonal variations of PAHs in urban atmospheric particles}

Total concentrations of PAHs, oxy-PAHs, benzothiophenes and methyl-PAHs in size-segregated samples of urban atmospheric particles at Japan National Route 463 in Sakura-Ku in downtown Saitama were obtained from 167 hours sampling periods performed from November to December during 2013 sampling campaign periods in Saitama, Japan shown in figure 1 and figure 2. SPM, $\mathrm{PM}_{2.5}$ and meteorological data were provided by the government pollutant monitoring station called "Saitama City Station" [11] located close to the ambient sampling site. The average concentrations of 37 species of particulate PAHs including methyl-PAHs, benzothiophenes and oxy-PAHs from atmospheric oxidation of PAHs was 3.42 to $6.51 \mathrm{ng} / \mathrm{m}^{3}$ during 2013 sampling campaign periods in Saitama, Japan. The average concentrations obtained for most PAHs in this study were significantly lower than literature data [12-13]. The main reason for these lower concentrations is that strict regulations placed on diesel exhaust particles came into effect in Tokyo in 2003, reducing the ambient amount of particulate matter.

The variation of PAHs concentrations was caused by different meteorological conditions. Compared with the correlations between the PAHs concentrations with ambient temperature $(\mathrm{r}=-0.14)$ and relative humidity $(\mathrm{r}=$ -0.09), the wind speed exerted a higher negative correlation with the concentrations of particulate PAHs $(r=-0.67)$, indicating that the wind speed was the major factor that influenced the concentrations of particulate PAHs in winter (figure 1). Additionally, these was high correlations between PAHs concentrations with SPM $(r=0.71)$ and $\mathrm{PM}_{2.5}(\mathrm{r}=0.84)$ (figure 2). In summer, high temperatures and strong UV radiation increased the transition and partition of PAHs from the particulate phase to the vapor phase and increased the photochemical decomposition of the PAHs. Conversely, in winter, the lower temperatures slowed the rate of photolysis and radical degradation; these factors combined with an increase in domestic heating and consumption of fuels could result in higher levels of particulate PAHs [12]. Lower mixing heights and less dispersion and gaseous diffusion in winter may contribute to high concentrations of PAHs during the winter season [13]. In addition, the photochemical degradation that is usually a significant loss process of PAHs [14-16] may be less efficient in winter and also contribute to the higher concentrations. Although the PAHs were significantly lower in this study than literature data, the seasonal variations of PAHs in urban atmospheric particles seemed to be similar with them. It is suggested that PAHs may be emitted from similar kinds of pollution sources.

\subsection{Size distribution of PAHs in urban atmospheric particles}

Figure 3 shows the different size distribution of the individual PAHs concentrations in November-December during 2013 sampling campaign periods 
in Saitama, Japan. As shown in figure 3, the low-molecular weight PAHs concentrations exhibited the nearly equal size distribution from stage $\leqq 1.1 \mu \mathrm{m}$ to stage $\geqq 7.0 \mu \mathrm{m}$. The high-molecular weight PAHs increased in inverse correlation to the particle size. In addition, figure 3 shows that the high-molecular weight PAHs were adsorbed on the finer particles, whereas the more volatile PAHs were associated with the larger particles.

Figure 4 shows the different particle sizes of the total PAHs concentrations in November to December during 2013 sampling campaign periods in Saitama, Japan. As shown in figure 4, the PAHs concentrations below $1.1 \mu \mathrm{m}$ was higher in autumn and winter. As mentioned above, in winter, the lower temperatures slowed the rate of photolysis and radical degradation; these factors combined with an increase in domestic heating and consumption of fuels could result in higher levels of particulate PAHs. Lower mixing heights and less dispersion in winter may contribute to these high winter concentrations.

One explanation for these results is that the higher molecular PAHs, which have much lower subcooled liquid vapor pressures and Henry constant are expected to require a much longer time to partition to coarse particles than the lower molecular PAHs and, thus, tend to remain in the fine particles [17]. Moreover, more unstable PAHs volatilized more rapidly from the fine particles than these non-volatile PAHs and sorbed onto the coarse particles. Another explanation for the results is that the chemical affinities between the PAHs and different size particles, along with different emission sources and different PAHs reactivities by photooxidation resulted in the differences in the PAH distribution with respect to different particle sizes [17, 18]. Therefore, PAHs in urban atmospheric fine particles will pose the stronger toxicity and do greater harm to human health. The slightly lower percentage in summer may be due to meteorological conditions and complicated interactions among many different emission sources of PAHs. It is also necessary to investigate the toxicity of 37 species of PAHs which were not only derived from vehicle emission with long range transportation, but also produced by local other anthropogenic sources.

The higher concentrations of $\mathrm{OH}, \mathrm{NO}_{3}$ and $\mathrm{O}_{3}$ radicals in summer suggests that the relative importance of secondary formation of oxy-PAHs will be high in summer since 1,8-NA was $0.83 \mathrm{ng} / \mathrm{m}^{3}$ in August, 2013. However, because 1.40 $\mathrm{ng} / \mathrm{m}^{3}$ in January, 2014, it may be presumed that the concentrations of 1,8-NA in winter will be the highest among all seasons. Oxidation reactions of PAHs in the atmosphere are mainly initiated through reaction with these radicals, which are present in high concentrations in summer [14, 19, 20], as well as atmospheric oxidation of PAHs [21-25].

In other laboratory experiments [26-28], it was reported that 1,8-NA could be formed by the oxidation of several PAHs, such as acenaphthylene, acenaphthene and even those with more than three rings like benz[a]anthracene. In addition, Kamens et al. [14] conducted outdoor chamber experiments where diluted wood smoke was exposed to midday natural sunlight and found that particle-associated 1,8-NA increased in concentrations with time in the presence of the sunlight (and low photochemical $\mathrm{O}_{3}$ accumulation, i.e. $<0.06 \mathrm{ppm}$ ). For the 
same reason, atmospheric environment of summer promotes atmospheric decomposition of PAHs. Furthermore, lower mixing heights and less dispersion in winter may contribute to these high winter concentrations.

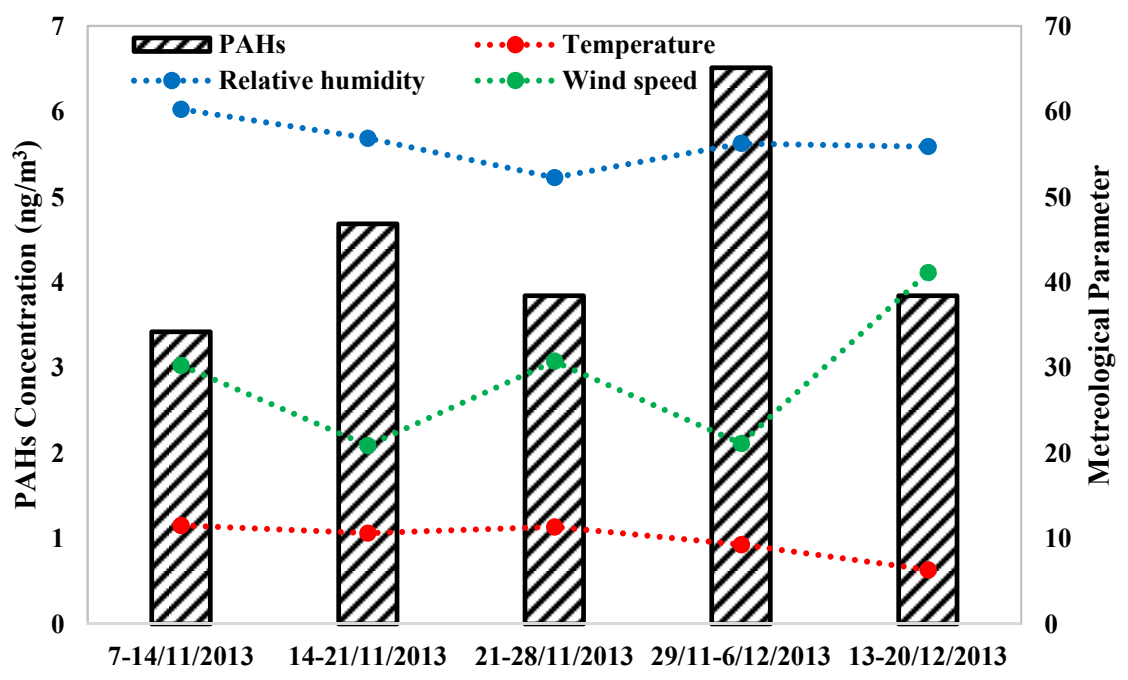

Figure 1: $\quad$ PAHs concentrations $(\mathrm{ng} / \mathrm{m} 3)$, temperature $\left({ }^{\circ} \mathrm{C}\right)$, wind speed $(0.1 \mathrm{~m} / \mathrm{s})$ and relative humidity (\%) from Nov. to Dec., 2013.

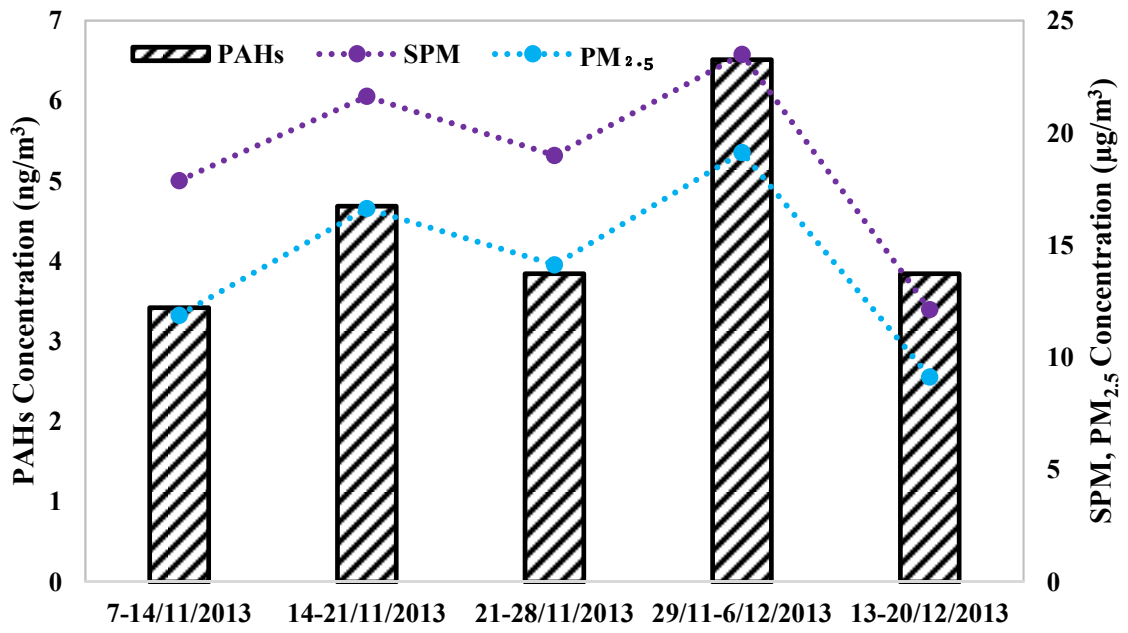

Figure 2: Concentrations of PAHs $\left(\mathrm{ng} / \mathrm{m}^{3}\right)$, SPM $\left(\mu \mathrm{g} / \mathrm{m}^{3}\right), \mathrm{PM}_{2.5}\left(\mu \mathrm{g} / \mathrm{m}^{3}\right)$ measured from Nov. to Dec., 2013 in Saitama, Japan. 


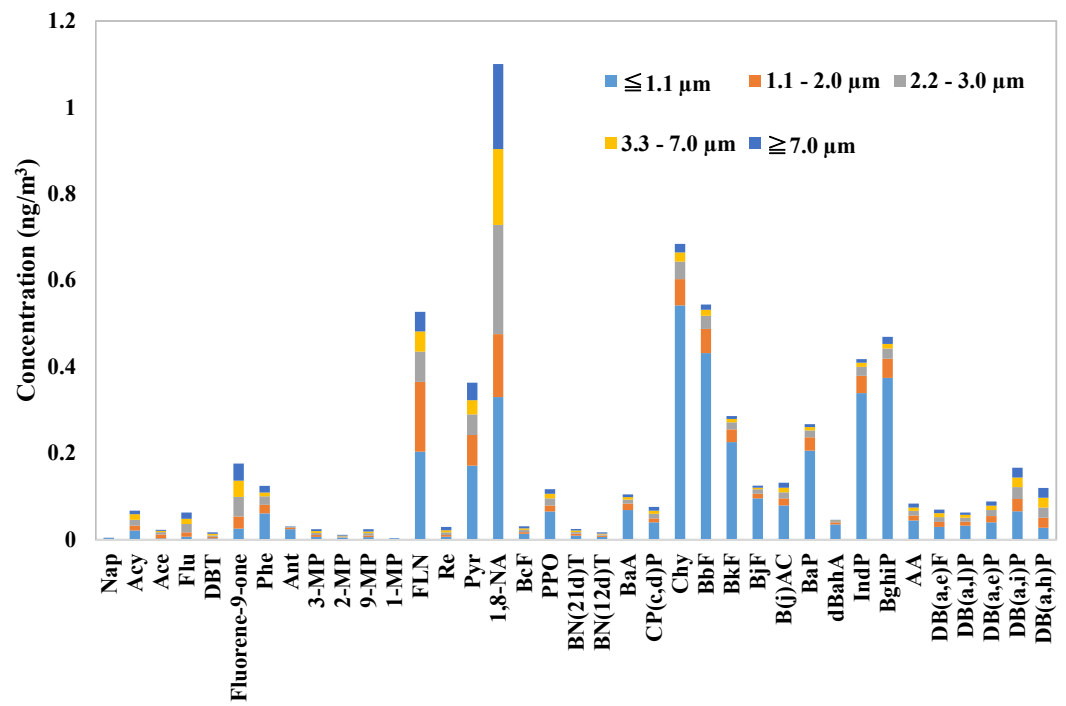

Figure 3: $\quad$ Size distribution of PAHs concentrations from Nov. to Dec., 2013.

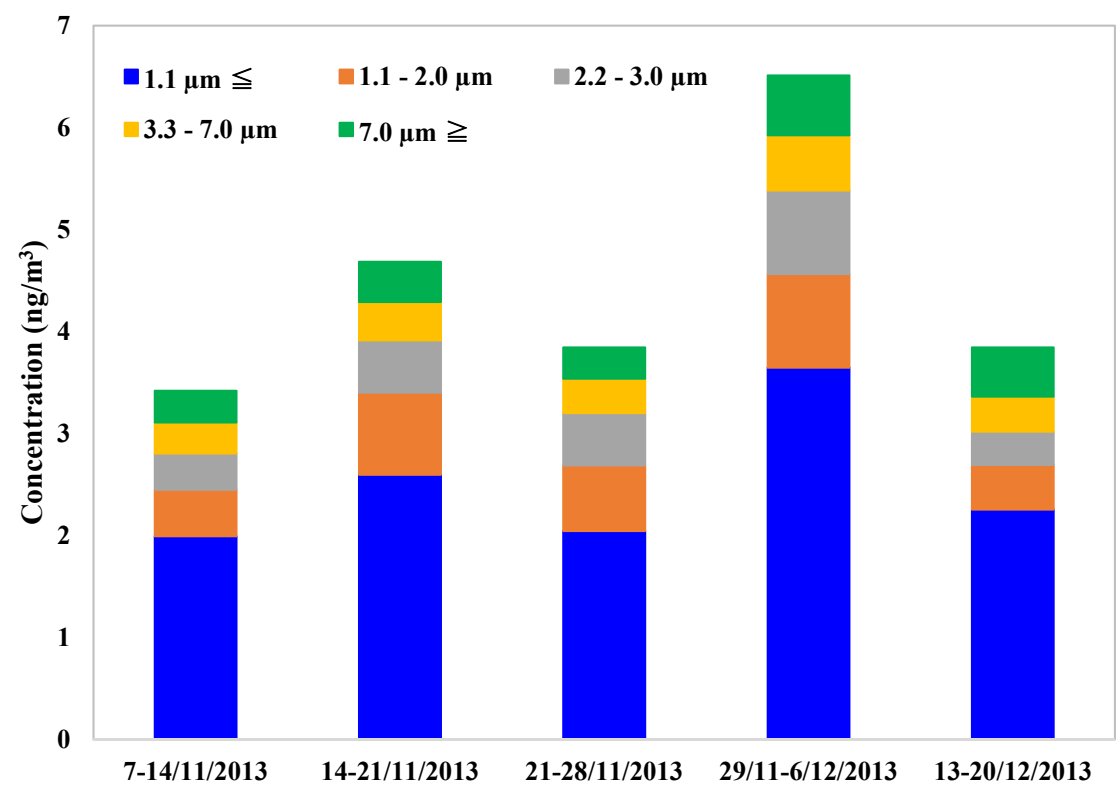

Figure 4: Size distribution of total PAHs concentrations from Nov. to Dec., 2013 in urban atmosphere of Saitama, Japan. 
In addition, the photochemical degradation that is usually a significant loss process of PAHs may be less efficient in winter and contribute to the higher concentrations. Therefore, the contribution of atmospheric formation to 1,8-NA concentrations is expected to be significant. The effect of secondary formation on the total concentrations of 37 species of PAHs would be dependent on the atmospheric concentrations of their precursors and the reaction rate of formation of the oxy-PAHs.

The cancer potency of each PAHs was assessed on the basis of its benzo $[a]$ pyrene equivalent concentrations (BaPeq). And U.S. Environmental Protection Agency's (U.S. EPA's) Integrated Risk Information System (IRIS) Program is releasing for scientific review a relative potency factor (RPF) approach for polycyclic aromatic hydrocarbon (PAH) mixtures as one approach for assessing cancer risk from exposure to PAH mixtures. RPF shows that benzo $[j]$ aceanthrylene, $\operatorname{dibenzo}[a, h]$ anthracene, benzo $[c]$ fluorene and dibenzo $[a, l]$ pyrene has high toxicity compared with benzo[a]pyrene. These PAHs concentrations were lower than BaP. So, it is the possibility that PAH's individual toxicity values is in large part responsible for effect on human health than the concentrations, like doxines.

\section{Conclusion}

In this study, seasonal concentrations and size distribution of 37 species of PAHs were investigated in urban site of Saitama, Japan. The average concentrations of particulate PAHs was 3.42 to $6.51 \mathrm{ng} / \mathrm{m}^{3}$ during the sampling campaign periods in the Saitama urban atmosphere. The wind speed exerted a higher negative correlation with the concentrations of particulate PAHs $(r=-0.67)$, indicating that the wind speed was the major factor that influenced the concentrations of particulate PAHs in winter. In winter, the lower temperatures slowed the rate of photolysis and radical degradation. Lower mixing heights and less dispersion in winter may contribute to these high winter concentrations. In addition, the photochemical degradation that is usually a significant loss process of PAHs may be less efficient in winter and also contribute to the higher concentrations.

The concentrations of low-molecular PAHs exhibited the nearly equal distribution from fine particles $\leqq 1.1 \mu \mathrm{m}$ to coarse particles $\geqq 7.0 \mu \mathrm{m}$. The high-molecular weight PAHs increased in inverse correlation to the particle size. The concentrations of 1,8-NA was the highest in 37 species of PAHs and it is possible a considerable fraction of $1,8-\mathrm{NA}$ in the atmosphere originates from atmospheric oxidation of PAHs.

PAHs in fine particles will pose a stronger toxicity and do greater harm to human health. The slightly lower fraction in summer may be due to meteorological conditions and complicated interactions among many different emission sources of PAHs. Toxicity of PAHs are concentrated in micro particle sizes. In consideration of the carcinogenic, mutagenic PAHs, the new measures against to toxic chemical composition in $\mathrm{PM}_{2.5}$ are required even locally in urban areas of Japan. Moreover, it is needed to face the long range transportation of regional air pollutants. 


\section{Acknowledgements}

Some works of this study are supported by the Special Funds for Basic Research (B) (No. 17310031, FY2005-FY2007) and Innovative Area Research (No. 20120015, FY 2008-FY2013) of Japanese Ministry of Education, Culture, Sports, Science and Technology (MEXT) and the FY2007-FY2008 Research project of Innovative Research Organization, Saitama University, Japan.

\section{References}

[1] Gaffney, J.S., Marley, N.A., The impacts of combustion emissions on air quality and climate - From biofuels and beyond, Atmospheric Environment, 43, 23-36 (2009).

[2] White, P.A., The genotoxicity of priority polycyclic aromatic hydrocarbons in complex mixtures, Mutation Research, 515, 85-98 (2002).

[3] IARC Monographs on the Evaluation of the Carcinogenic Risk of Chemicals to Humans, Suppl, 7, Lyon (1987).

[4] Villalobos-Pietrini, R., Hernández-Mena, L., Amador-Muñoz, O., Munive-Colín, Z., Bravo-Cabrera, J.L., Gómez-Arroyo, S., Frías-Villegas, A., Waliszewski, S., Ramírez-Pulido, J., Ortiz-Muñoz, R., Biodirected mutagenic chemical assay of PM10 extractable organic matter in Southwest Mexico City, Mutation Research, 634, 192-204 (2007).

[5] Venkataraman, C., Lyons, J.M., Friedlander, S.K., Size distributions of aromatic hydrocarbons and elemental carbon. 1. Sampling, measurement methods and source characterization, Environmental Science \& Technology, 28, 555-562 (1994).

[6] Allen, A.G., Rocha, G.O., Cardoso, A.A., Paterlini, W.C., Machado, C.M.D., Andrade, J.B., Atmospheric particulate polycyclic aromatic hydrocarbons from road transport in southeast Brazil, Transportation Research Part D: Transport and Environment, 13, 483-490 (2008).

[7] Kurihara R, Shiraishi F, Tanaka N, Hashimoto S, Presence and estrogenicity of anthracene derivatives in coastal Japanese waters, Environ. Toxicol. Chem, 1984-93 (2005).

[8] Lundstedt S, White PA, Lemieux CL, Lynes KD, Lambert LB, Oberg L, et al. Sources, fate, and toxic hazards of oxygenated polycyclic aromatic hydrocarbons (PAHs) at PAH-contaminated sites, Ambio, 36, 475-85 (2007).

[9] Duan JC, Bi XH, Tan JH, Sheng GY, Fu JM, Seasonal variation on size distribution and concentration of PAHs in Guangzhou city, China, Chemosphere, 67, 614-22 (2007).

[10] WHO, IARC Monographs on the Evaluation of Carcinogenic Risks to Humans, Volume 92 Some Non - heterocyclic Polycyclic Aromatic Hydrocarbons and Some Related Exposures (2010).

[11] Saitama prefecture official website (last access: 23 February 2014), http://www.pref.saitama.lg.jp/site/dousei1001/dousei901.html Japanese). 
[12] $\mathrm{Hu}$ J, Liu CQ, Zhang GP, Zhang YL. Seasonal variation and source apportionment of PAHs in TSP in the atmosphere of Guiyang, Southwest China. Atmos Res, 118, 271-9 (2012).

[13] Bamford, H.A., Baker, J.E., Nitro-polycyclic aromatic hydrocarbon concentrations and sources in urban and suburban atmospheres of the Mid-Atlantic region, Atmospheric Environment, 37, 2077-2091 (2003).

[14] Kamens, R.M., Karam, H., Guo, J., Perry, J.M., Stockburger, L., The behavior of oxygenated polycyclic aromatic hydrocarbons on atmospheric soot particles, Environmental Science and Technology, 23, 801-806 (1989).

[15] Barbas, J.T., Sigman, M.E., Dabestani, R., Photochemical oxidation of phenanthrene sorbed on silica gel, Environmental Science and Technology, 30, 1776-1780 (1996).

[16] Fioressi, S., Arce, R., Photochemical transformations of benzo[e]pyrene in solution and adsorbed on silica gel and alumina surfaces. Environmental Science and Technology, 39, 3646-3655 (2005).

[17] Allen JO, Dookeran NM, Smith KA, Sarofim AF, Taghizadeh K, Lafleur AL. Measurement of polycyclic aromatic hydrocarbons associated with size-segregated atmospheric aerosols in Massachusetts, Environmental Science and Technology, 30, 1023-31 (1996).

[18] Venkataraman C, Thomas S, Kulkarni P. Size distributions of polycyclic aromatic hydrocarbons-gas/particle partitioning to urban aerosols. $J$ Aerosol Sci, 30, 759-70 (1999).

[19] Helmig, D., Arey, J., Atkinson, R., Harger, W.P., McElroy, P.A., Products of the $\mathrm{OH}$ radical-initiated gas-phase reaction of fluorene in the presence of NOx, Atmospheric Environment, 26, 1735-1745 (1992a).

[20] Wang, L., Atkinson, R., Arey, J., Formation of 9,10-phenanthrenequinone by atmospheric gas-phase reactions of phenanthrene, Atmospheric Environment, 41, 2025-2035 (2007).

[21] Pitts Jr., J.N., Cauwenberghe, K.V., Grosjean, D., Schmid, J.P., Fitz, D.R., Belser, W.L., Knudson, G.P., Hynds, P.M., Atmospheric reactions of polycyclic aromatic hydrocarbons: facile formation of mutagenic nitroderivatives, Science, 202, 515-519 (1978).

[22] Arey, J., Zielinska, B., Atkinson, R., Winer, A.M., Ramdahl, T., Pitts Jr., J.N., The formation of nitro-PAH from the gas-phase reactions of fluoranthene and pyrene with the $\mathrm{OH}$ radical in the presence of $\mathrm{NOx}$, Atmospheric Environment, 20, 2339-2345 (1986).

[23] Zielinska, B., Arey, J., Atkinson, R., Ramdahl, T., Winer, A.M., Pitts Jr., J.N., Reaction of dinitrogen pentoxide with fluoranthene. Journal of the American Chemical Society, 108, 4126-4132 (1986).

[24] Kameda, T., Takenaka, N., Bandow, H., Inazu, K., Hisamatsu, Y., Determination of atmospheric nitro-polycyclic aromatic hydrocarbons and their precursors at a heavy traffic roadside and at a residential area in Osaka, Japan, Polycyclic Aromatic Compounds, 24, 657-666 (2004).

[25] Albinet, A., Leoz-Garziandia, E., Budzinski, H., Villenave, E., Jaffrezo, J.L., Nitrated and oxygenated derivatives of polycyclic aromatic hydrocarbons in the ambient air of two French alpine valleys: part 1: 
concentrations, sources and gas/particle partitioning, Atmospheric Environment, 42, 43-54 (2008).

[26] Sigman, M.E., Chevis, E.A., Brown, A., Barbas, J.T., Dabestani, R., Burch, E.L., Enhanced photoreactivity of acenaphthylene in water: a product and mechanism study, Journal of Photochemistry and Photobiology A: Chemistry, 94, 149-155 (1996).

[27] Reyes, C., Sigman, M.E., Arce, R., Barbas, J.T., Dabestani, R., Photochemistry of acenaphthene at a silica gel/air interface, Journal of Photochemistry and Photobiology A: Chemistry, 112, 227-283 (1998).

[28] Lee, B.D., Iso, M., Hosomi, M., Prediction of Fenton oxidation positions in polycyclic aromatic hydrocarbons by Frontier electron density, Chemosphere, 42, 431-435 (2001). 